\title{
Stereoselective Synthesis of (+)-Methyl 8-epi-nonactate ${ }^{\dagger}$
}

\author{
Eun Lee, ${ }^{*}$ Lex Taek Sung, and Sung Kil Hong

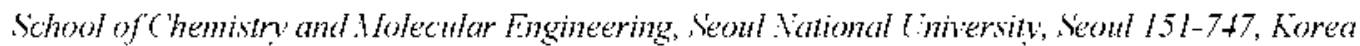 \\ Received Fehruary 6, 2002
}

Key Words : 8-epi-Nonactate. $\beta$-Alkoxymethacry lates. Radical cyclization

It is now well established that cis-2.5-disubstituted tetrahydrofurans and cis-2.6-disubstituted tetrahydropyrans are obtained stereoselectively via radical cyclization of $\beta$ alkoxyacrylates.' Use of $\beta$-alkoxymethacrylates leads to products possessing an extra stereogenic center outside the ring, and stereocontrol therein is possible by hydrogen transfer under low temperature conditions: stereoselective synthesis of $(+)$-methyl nonactate was achieved in this fashion. ${ }^{2}$ More recently a total synthesis of pamamycin-607 was accomplished. ${ }^{3}$ in which a key $\beta$-alkoxymethacrylate substrate was employed in a radical cyclization step. Feigrisolide C (1) ${ }^{4}$ is a newly discovered antibiotic macrodiolide featuring $(+)-8$-e $\mathrm{p}$-nonactic acid moiety (Scheme 1). and we wish to report here a stereoselective synthesis of $(+)$ methyl 8-e pi-nonactate (2)

The known diol $4^{5}$ was obtained from methyl $(R)-3-$ hydroxy butyrate (3) wia Weinreb anide formation. vinyl Grignard addition. and stereoselective reduction ${ }^{7}$ using sodium borolydride and triethy lborane (Scheme 2). Hydroboration-oxidation of the benzylidene acetal of 4 produced the primary alcohol 5 . Regioselective alane reduction ${ }^{8}$ of alcohol 5 and the subsequent tosylation provided the secondary alcohol 6. The pivotal $\beta$-alkoxymethacrylate intermediate 7 was prepared by the reaction of alcohol 6 with excess methyl 3.3-dimethoxy-2-methylpropanoate in the presence of an acid catalyst.

When the $\beta$-alkoxymethacrylate 7 was allowed to react with tris(trimethylsilyl)silane in the presence of trietlyylborane at $-20{ }^{\circ} \mathrm{C}$. the desired threo isomer 8 was stereoselectively ( $16: 1$ ) obtained in $74 \%$ y ield (Scheme 3 ). Using tributy Istamane as the hydrogen-transferring agent at -78 "C. an improved yield $(92 \%)$ of the threo isomer 8 was
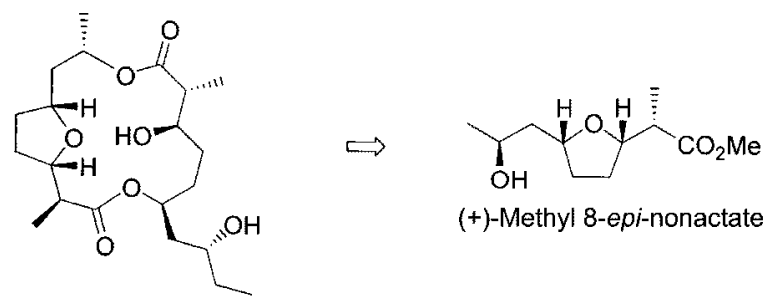

(+)-Methyl 8-epi-nonactate (2)

Feigrisolide $C(1)$

\section{Scheme 1}

I) Jedicated to f'rof. Sang C.'Tul Shim, a scholar, teacher, and statesman in chemistry

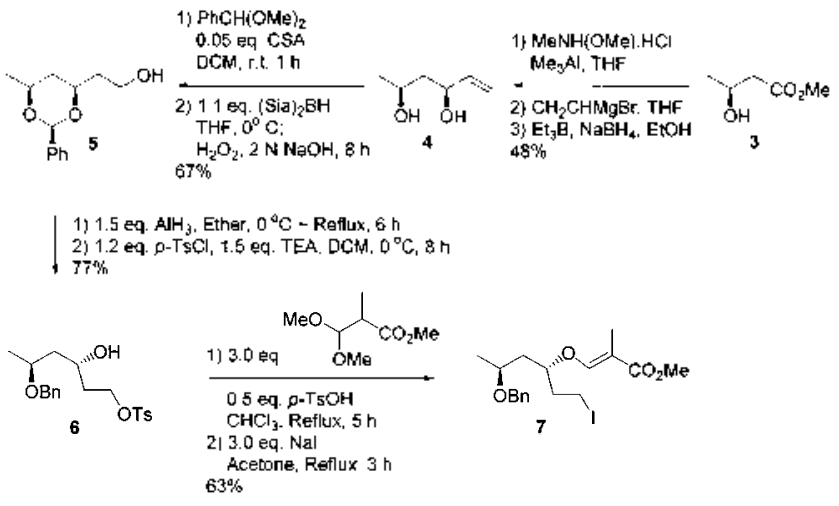

Scheme 2

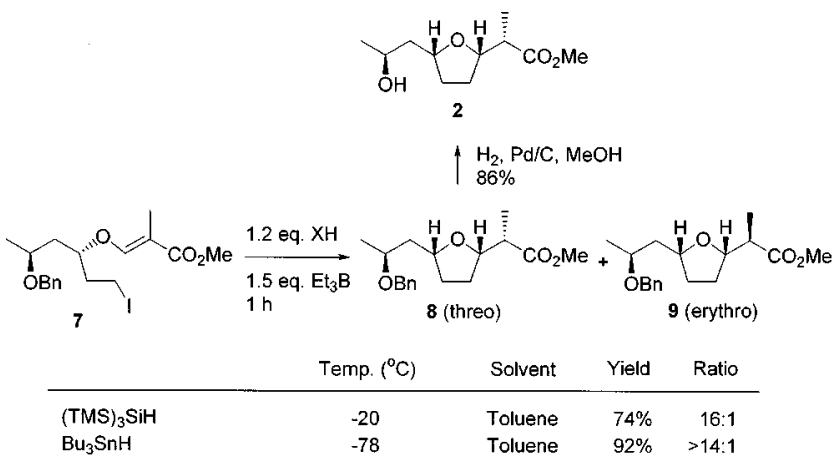

Scheme 3

obtained with similar stereoselectivity $(>1+: 1) .(+)$-Methyl 8 -epi-nonactate (2) was funally prepared via hydrogenolysis of benzyl ether 8 .

In this synthesis. the threo selectivity was maintained in the $\beta$-alkoxymethacrylate radical cyclization providing a further example of stereocontrol in radical reactions.

Acknowledgment. The authors thank the Ministry of Science and Technology. Republic of Korea, and Korea Institute of Science and Tecluology Evaluation and Planuing for a National Research Laboratory grant (1999). A Brain Korea 21 graduate fellowship grant to L. T. Sung is gratefully acknowledged.

\section{References}

1. For selected examples of $\beta$-alkoxyacrylarc radical cyclizations. see: (a) Lee. E.: Tac. J. S.: Loc. C.: Park. C. M. Tetrohedron Lett. 
1993. 34. 4831-4834, (b) Lec. E.: Park. C. M.: Yun. J. S. $J$. Lm. (hem. Soc. 1995, 117, 8017-8t)18. (c) I.ee t:. Yoo, S-K.: Cho, Y.S.: Cheon. II.S.: Chong. Y. 11. Fetraheatron tett 1997, 38. 7757-7758. (d) J.ee. 1:. Yoo. S.-K: Choo, H.: Song- H. Y. Tthutedron Lett. 1998. 39.317-318. (c) Lee. E.: Choi. S. J.: Kim. H.: Han. H. O.: Kim. Y. K.: Min. S. J.: Son. S. H.: Lim. S. M.: Jang. W. S. Angen: (Them. Int Ld. 2002. 41. 176-178. (1) Lec. E.: Song. II. Y. Kang. I. W.: Kim. 1).S. Jung C -K. Joo, J. M. $J$. Am. Chem. Soc 21Mn 2 124, 384-385. (g) Jior lurther relerences. see: 1.ee. 1: lu Rudiculs in Orgunic Sinthesis, Iol 2: Applications: Renaud. P.. Sibi. M. P.. Eds.: Wilcy-VCH: Weinheim. 2001: pp 30)3-333.

2. Lec. E.: Choi. S. J. Org Lett 1999. I. 1127-1128.

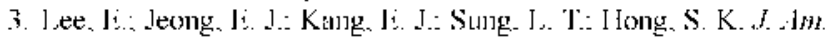
(Them. Soc. 2001. 123,1013]-10132.
4. Tang. Y.-Q.: Sattler. I.: Thicricke. R.: Grabley. S f ththiot. 2 MMI. $53.934-943$

5. Preparation of (-)-methyl 8-epi-nonactale wals reported in conjunetion with the svinthesis of nonatin: (a) Bartlett. P. A. Meadows. T. D.: Ottow: E. J. Am. Chem. Soc. 1984. 106. 53045311. (b) Kim. B. H.: Lec. T. Y. Tetrahedrom Letf. 1992. 33. 2557-2560. (c) Lee. J. Y.: Kim. B. H. Tetrahedron 1996. 52. 571588

6. (a) Mohr. P. lamm. C. Tetrdedron Lett. 1987. 28. 395-396. (b) Mohr. P. Totrahedron Lu'ff 1992, 33, 2455-2458.

7. Chen. K.-M.: Gunderson. K. G.: Hardtmant1. G. E.: Prasad. K.: Repic. O.: Shapiro. M. J. (Them. Leff. 1987. 1923-1926.

8. Alane reduction of 5 proceeded with high regioselectivity: Lipták. A. Jodil I.: Numasi. P. Carbohud: Res. 1975. 44, l-1 I

9. Walkup, R. 1). Obevesekere. N. U. Sunthesis 1987. 6,07-61 1. 